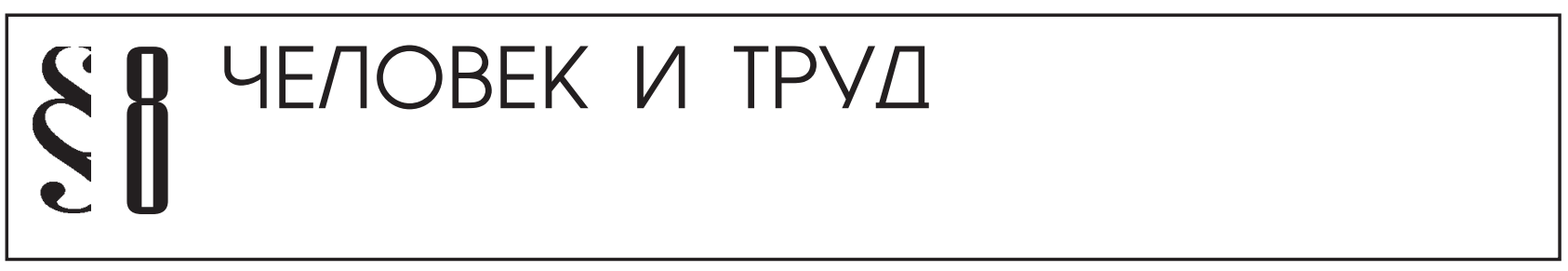

М.В. Макарова

\title{
ЗАНЯТОСТЬ ИНВАЛИДОВ В РОССИЙСКОЙ ФЕДЕРАЦИИ
}

\begin{abstract}
Аннотация: Аннотаџия: в статье рассматривается специфика политики занятости инвалидов, факторы, способствуюшие дифференциации среди инвалидов, соџиальная стагнаџия. Инвалиды в России составляют значительную часть малоимущего населения, к тому же чаще они относятся к наибеднейтей группе и страдают от недостатка жилья, общественного транспорта и медицинского обслуживания. Возможности трудоустройства у них маль, а другие способы получения дохода практически недоступны. На сегодняшний день экономический «инфляиионный» рост приводит к социальной стагнации. Формируется группа людей, которая не может приобрести качественные товары, жилье и прочие блага. Если обеспечить возможность получить таким людям, которые не входят ни в категорию бедных, но при этом очень далеки от среднего класса, качественное образование, то в будущем им можно выйти на более престижный рынок труда. Законодательством Российской Федерации никаких ограничений в области занятости инвалидов по видам профессий не предусмотрено.
\end{abstract}

Ключевые слова: Политология, труд, политика, общество, инвалиды, занятость, государство, право, конфликт, соииальные технологии

$\mathrm{Y}$ лучшение условий жизни инвалидов как одной из самых социально уязвимых категорий населения, их адаптация и интеграция в общество входят в число приоритетных задач, определенных в посланиях Президента Российской Федерации Федеральному Собранию Российской Федерации. Российская Федерация провозглашена как социальное государство, поэтому обязано заботиться о детях, пенсионерах, о людях с ограниченными трудовыми и физическими способностями и других социально незащищенных гражданах.

Ограниченная трудоспособность и недоступность традиционных форм занятости для лиц с ограниченными возможностями здоровья (ОВ3) становятся серьезными препятствиями к получению дохода, и, соответственно, повышают риск оказаться среди группы бедных.

Инвалиды в России составляют значительную часть малоимущего населения, к тому же чаще они относятся к наибеднейшей группе и страдают от недостатка жилья, общественного транспорта и медицинского обслуживания. Возможности трудоустройства у них малы, а другие способы получения дохода практически недоступны. На сегодняшний день экономический «инфляционный» рост приводит к социальной стагнации. Формируется группа людей, которая не мо- жет приобрести качественные товары, жилье и прочие блага. Если обеспечить возможность получить таким людям, которые не входят ни в категорию бедных, но при этом очень далеки от среднего класса, качественное образование, то в будущем им можно выйти на более престижный рынок труда. Законодательством Российской Федерации никаких ограничений в области занятости инвалидов по видам профессий не предусмотрено.

По оценкам Всемирного Банка, около семидесяти процентов инвалидов, имеющих нарушения здоровья средней и тяжелой степени, живут за чертой бедности. Бедность и инвалидность тесно взаимосвязаны, вместе они повышают уязвимость населения и усугубляют социальную изоляцию.

Социальная структура российского общества сегодня выглядит так: богатые составляют, по проведенным исследованиям, 2-3 процента, средний класс 20 процентов, бедные - 10. А 70 процентов составляют класс «ниже среднего», из которых 33 процента имеют шансы присоединиться к среднему классу, а 37, наоборот, рискуют оказаться бедными ${ }^{1}$. Люди с ограни-

\footnotetext{
1 Дискуссия по секции 4 по теме «Меры по содействию занятости граждан, испытывающих трудности на рынке
} 
Человек и труд

ченными возможностями, одинокие матери, и другие льготные категории граждан входят в эту рисковую группу.

Среди факторов, способствующих бедности среди инвалидов в России, наиболее важными являются следующие:

1) инвалиды имеют низкий уровень образования: в 2011 году по всем формам обучения в государственных и муниципальных вузах обучалось более 19 тысяч инвалидов, в государственных ссузах - более 13 тысяч. По данным проведенного Минобрнауки РФ в 2010 году мониторинга наличия условий для обучения инвалидов в подведомственных вузах, к началу этого года беспрепятственный доступ инвалидов на свою территорию обеспечили не более $5 \%$ от общего количества учреждений. Частично такие условия были созданы в $25 \%$ вузов.
2) среди инвалидов наблюдается низкий уровень занятости. Занятость инвалидов позволяет решить основную проблему бедности инвалидов - получение дохода. К административным механизмам содействия занятости относят квотирование и обращения в службы занятости.

Для наглядной иллюстрации автор считает необходимым привести данные пилотного исследования, проводимого в научно-исследовательской лаборатории по проблемам профессионального в рамках научно-исследовательской работы. ${ }^{2}$

В ходе исследования было опрошено 57 студентов 5 курса МГГЭИ, из них 26 юношей, 19 девушек, и 12 человек, не имеющие нарушения в опорно-двигательной системе.

На вопрос «Работаете ли вы сейчас?», ответы распределились следующим образом:

Таблицุа 1.

Распределение ответов на вопрос анкеть «Работаете ли вы сейчас»

\begin{tabular}{|c|c|c|c|c|c|}
\hline & & Частота & Процент & $\begin{array}{c}\text { Действительный } \\
\text { процент }\end{array}$ & Полезный процент \\
\hline & да & 14 & 24,6 & 30,4 & 30,4 \\
\hline & нет & 32 & 56,1 & 69,6 & 100,0 \\
\hline & Всего & 46 & 80,7 & 100,0 & \\
\hline $\mathrm{He}$ & ответившие & 11 & 19,3 & & \\
\hline Всего & & 57 & 100,0 & & \\
\hline
\end{tabular}

Диаграмма 1.
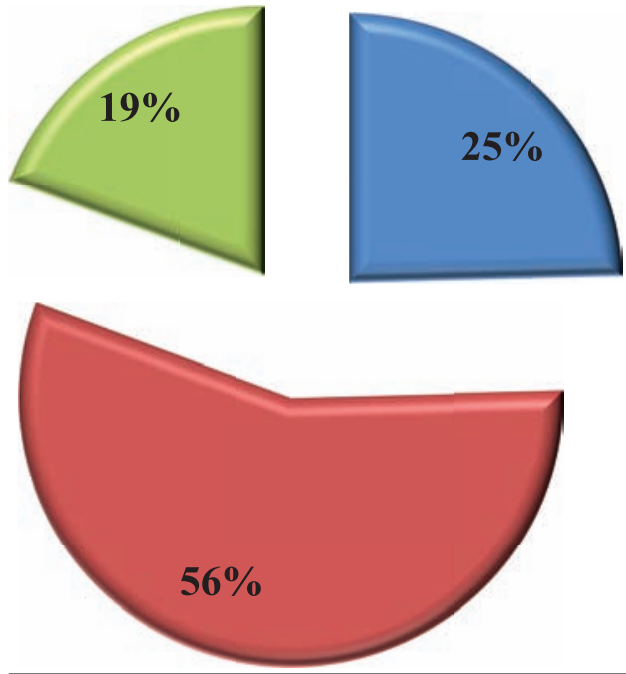

труда». Материалы конференции, организованной Министерством здравоохранения и социального развития Российской Федерации и Международной организацией труда. Москва, 15 сентября 2011 г.
Распределение ответов на вопрос анкеть «Работаете ли вы сейчас» да

Heт

затрудняюсь ответить 


\section{Политика и общество 5 (101) • 2013}

Интерпретируя табличные и графические данные, можно сказать, что большинство выпускников $(56,1 \%)$ не работает из всех опрошенных (100\%).

На вопрос «Считаете ли свой уровень знаний достаточным для трудоустройства по выбранной специальности?» ответы распределились следующим образом:
То есть из 45 ответивших студентов (имеющих нарушения в работе опорно-двигательной системы) достаточным уровнем образования для трудоустройства считают только 16 человек.

Можно привести данные о роли организаций, оказывающих содействие в трудоустройстве. В анкете был задан вопрос: «Какие организации

Таблича 2.

Распределение ответов на вопрос анкеты «Считаете ли свой уровень знаний достаточным для трудоустройства по выбранной специчальности?»

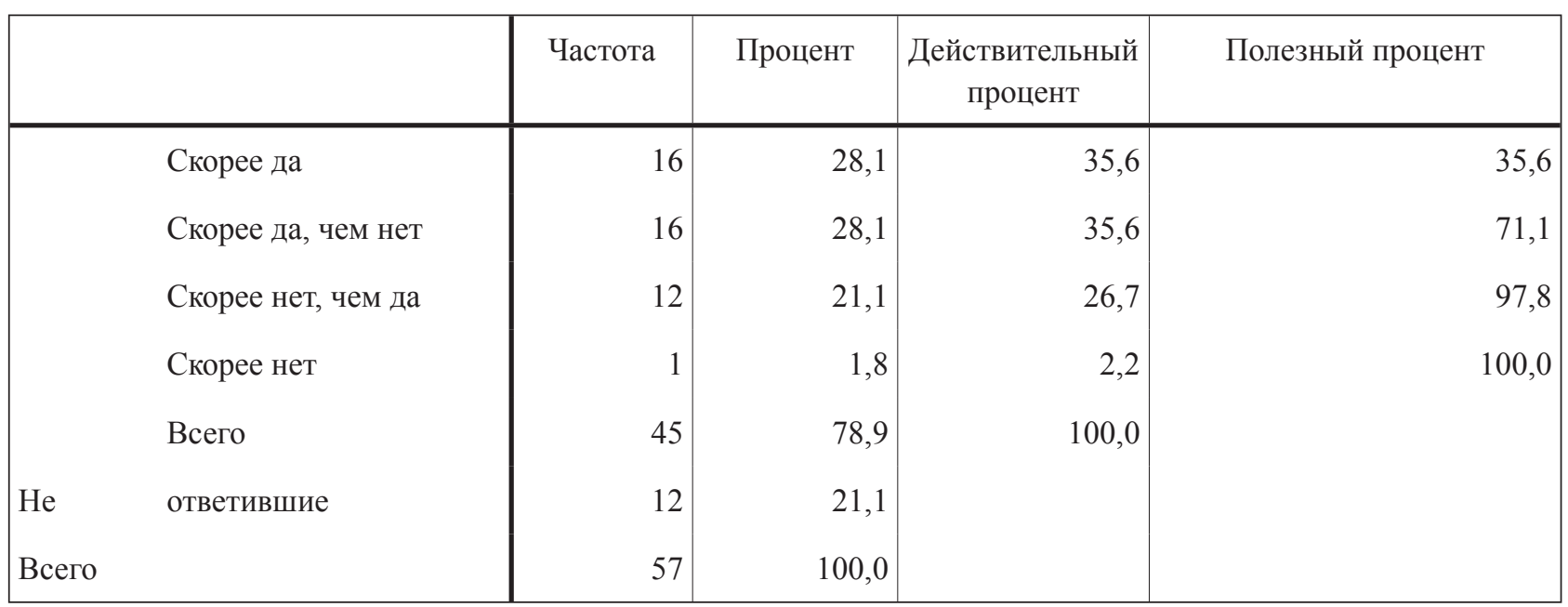

оказывают наиболее эффективную помощь в трудоустройстве?»

Ответы распределились следующим образом:

Таблица 3.

Распределение ответов на вопрос анкеты «Какие организации оказывают наиболее эффективную помощь в трудоустройстве?»

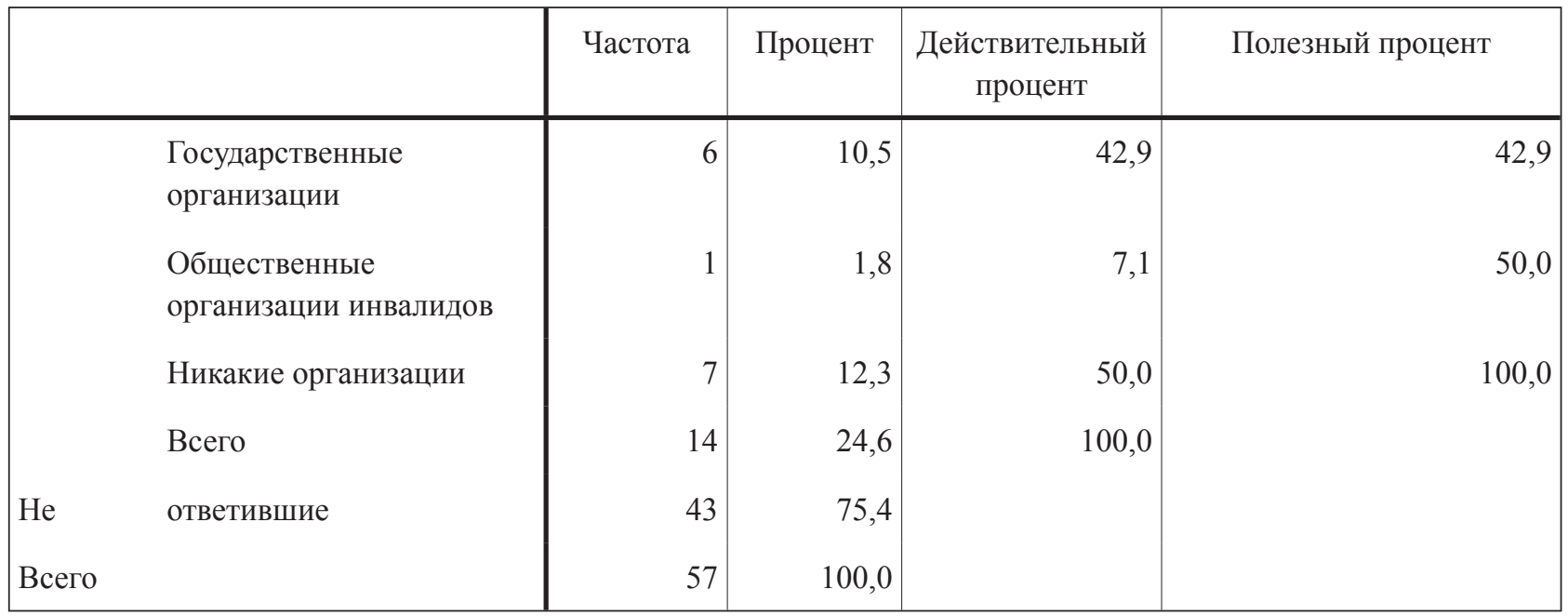


Человек и труд

Диаграмма 2. Какие организаиии оказывают наиболее эффективную помощь в трудоустройстве?

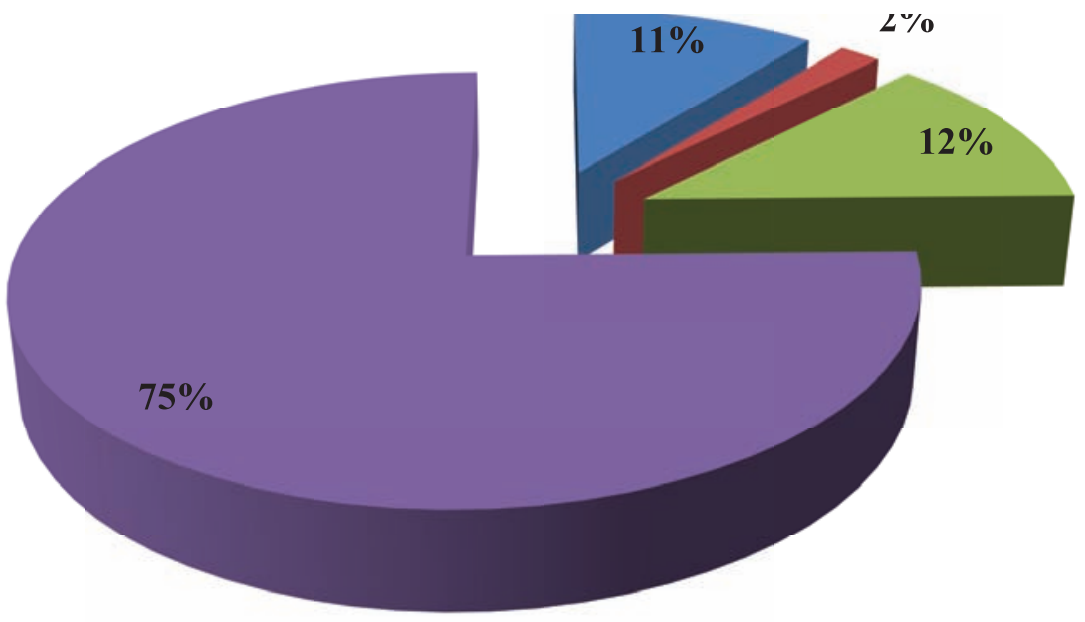

\section{Государственные организации - Никакие организации}

Полученные данные свидетельствуют о том, что большинство опрошенных студентов затрудняются ответить на этот вопрос, и, очевидно, не обращались за помощью в трудоустройстве.

Также в ходе исследования был задан вопрос о факторах, которые мешают работать эффективно и получать удовлетворение от своей трудовой деятельности.

\section{- Общественные организации инвалидов - Затрудняюсь ответить}

Таким образом, можно сделать общий вывод о том, что большинство выпускников не заняты каким-либо видом трудовой деятельности. Поэтому у них нет причин быть недовольными своей работой.

Возвращаясь к квотированию, следует отметить, что понятие «квота для приема на работу инвалидов» раскрывается в Федеральном законе «О социальной защите инвалидов в Российской Федерации». В этом

Таблица 4.

Распределение ответов на вопрос анкеты «Какие причины, на Ваш взгляд, дают людям с ограниченными возможностями основания быть недовольными своей работой?»

\begin{tabular}{|c|c|c|c|c|c|}
\hline & & Частота & Процент & $\begin{array}{l}\text { Дей с т в и тельный } \\
\text { процент }\end{array}$ & Полезный процент \\
\hline & $\begin{array}{l}\text { Выполнение монотонной } \\
\text { и неквалифицированной } \\
\text { работы }\end{array}$ & 3 & 5,3 & 23,1 & 23,1 \\
\hline & $\begin{array}{l}\text { Отсутствие возможности } \\
\text { пр о фе с с и она льн о го } \\
\text { роста }\end{array}$ & 5 & 8,8 & 38,5 & 61,5 \\
\hline & Низкая заработная плата & 1 & 1,8 & 7,7 & 69,2 \\
\hline & Затрудняюсь ответить & 4 & 7,0 & 30,8 & 100,0 \\
\hline & Всего & 13 & 22,8 & 100,0 & \\
\hline $\mathrm{He}$ & ответившие & 44 & 77,2 & & \\
\hline Всего & & 57 & 100,0 & & \\
\hline
\end{tabular}




\section{Политика и общество 5 (101) • 2013}

же законе есть соответствующая статья, которая устанавливает, что инвалидам предоставляются гарантии трудовой занятости федеральными органами государственной власти, органами государственной власти субъектов Российской Федерации. На региональном уровне предусмотрено проведение специальных мероприятий. К ним относятся:

- установление в организациях независимо от организационно-правовых форм квоты для приема на работу инвалидов;

- резервирование рабочих мест по профессиям, наиболее подходящим для трудоустройства инвалидов;

- стимулирование создания предприятиями, учреждениями, организациями дополнительных рабочих мест и другие меры.

Например, в Воронежской области действуют следующие программы, направленные на эффективное трудоустройство инвалидов: областная целевая программа содействия занятости инвалидов на 2010 2014 гг., долгосрочная областная целевая программа «Доступная среда на 2011-2015 гг.». По предварительным прогнозам, почти 11 тыс. инвалидов смогут воспользоваться государственными услугами в области содействия занятости. Это практически каждый третий незанятый инвалид, не имеющий противопоказаний к труду.

Люди с ограниченными возможностями - это особая категория людей, изначально поставленных в неравные условия, к которым нужно искать индивидуальные подходы.

К таким подходам можно отнести частичную компенсацию заработной платы тем работодателям, которые создают рабочие места сверх установленных квот. Можно привести как пример данные Федеральной службы по труду и занятости: $88,2 \%$ от общей численности граждан с ограниченными возможностями, которые обращаются в службу занятости, остаются там на учете. Средняя продолжительность периода безработицы среди этой категории достаточно высока: порядка 25\% людей состоят на учете 4-8 месяцев и чуть более $26 \%$ - свыше 8 месяцев.

Среди людей с ограниченными возможностями довольно эффективно работает программа самозанятости. Сегодня политикой занятости, в том числе и в плане трудоустройства людей с ограниченными возможностями, в России занимаются, как минимум, три министерства: Министерство труда и социальной политики, Министерство экономического развития и торговли, Министерство финансов. В стране отсут- ствует какой-либо институт, который согласовывает политики между различными органами государственного управления.

В ряде стран есть успешный опыт создания при совете министров рабочей группы или управленческой группы по вопросам согласования экономической политики и политики занятости. Такая группа подчиняется непосредственно руководителю правительства, таким образом, создается институциональный механизм, который обеспечивает согласованность этих политик³

Предприятия, которые открываются при помощи субсидий, получаемых от службы занятости, уходят в такие секторы экономики, которые не могут дать моментальной отдачи (например, сельскохозяйственные предприятия). Поэтому в качестве одной из рекомендаций можно предложить, чтобы такие субъекты получали налоговые льготы. Политика занятости должна рассматриваться не только как часть социальной, но и как часть экономической политики, и главная ее задача - это обеспечение экономического роста в стране.

Вся заявленная работодателями потребность в рабочей силе составила в 2010 году 76528 рабочих мест в счет квот для приема на работу инвалидов и других категорий, на которые распространяется квотирование $^{4}$. Это более $10 \%$ от всех вакансий, предоставленных работодателями в службу занятости. Для инвалидов в счет квот предоставлено более 52 тыс. рабочих мест, что составляет порядка 7\% от общего количества заявленных вакансий. В современных социально-экономических условиях ни один из заявленных административных механизмов регулирования занятости инвалидов не работает в полной мере.

Стабильное экономическое развитие, несомненно, позволит снизить уровень бедности в Российской Федерации. Тем не менее, улучшение условий жизни большинства не означает, что инвалиды также получат доступ к благам, появляющимся в результате экономического роста.

Ограничение свободы передвижения инвалидов вызывает снижение мотивации трудиться, получать образование, вызывает финансовую зависимость, и, как результат, понижение качества жизни.

\footnotetext{
${ }^{3}$ Вовченко A.B. Трудоустройство людей с ограниченными возможностями - нестандартная работа. Материалы конференции, организованной Министерством здравоохранения и социального развития Российской Федерации и Международной организацией труда. Москва, 15 сентября 2011 г.

${ }^{4}$ news.mail.ru/inregions/fareast/79/society/
} 
DOI: $10.7256 / 1812-8696.2013 .05 .9$

Человек и труд

До 2013 года все субъекты России в обязательном порядке примут от Министерства труда и социального развития РФ часть федеральных полномочий по обеспечению отдельных категорий граждан техническими средствами реабилитации и предоставлению услуг по социально-курортному лечению. Это телевизоры с приемом скрытых субтитров, телефонные устройства с текстовым выходом, оптические средства для коррекции слабовидения, магнитофоны, плееры для чтения «говорящих книг», тактильные трости. Самые востребованные технические средства у инвалидов - трости, костыли, кресла-коляски. Например, в Еврейском автономном округе в 2012 году выдано около 130 тысяч изделия.

Социальная политика основным инструментом выдвигает нормативно-правовую базу. Действующее законодательство в отношении инвалидов носит разветвленный характер: в нем содержатся гарантии занятости и профессиональной подготовки людей с ограниченными возможностями здоровья, получения ими достойного образования, охраны здоровья, социальной и правовой защиты, интеграции и реабилитации, участия в политической, социальной и культурной жизни, представления необходимой информации.

Государственная политика по вопросам интеграции инвалидов определена Ф3 «О социальной защите инвалидов в Российской Федерации», ФЗ от 27 июля 2010 г. № 210-Ф3 «Об организации предоставления государственных и муниципальных услуг», Постановлением Правительства Российской Федерации от 30 ноября 2005 г. № 708 «Об утверждении правил обеспечения инвалидов собаками-проводниками, включая выплату ежегодной денежной компенсации расходов на содержание и ветеринарное обслуживание собак-проводников» и другие 5

В законодательной базе предусмотрено достаточное количество льгот, которые существуют номинально. Очевидно, что реабилитация людей с ограниченными возможностями здоровья позволяет возвращать их к активной независимой жизни и труду, тем самым не только снижать нагрузку на бюджет, но и получать дополнительные финансовые средства для развития страны и регионов.

\footnotetext{
${ }^{5}$ Вовченко A.B. Трудоустройство людей с ограниченными возможностями - нестандартная работа. Материалы конференции, организованной Министерством здравоохранения и социального развития Российской Федерации и Международной организацией труда. Москва, 15 сентября 2011 г
}

Учреждения медико-социальной экспертизы по результатам освидетельствования разрабатывают индивидуальные программы реабилитации инвалидов на основе оценки ограничений жизнедеятельности, вызванных стойким расстройством функций организма, а также формируют рекомендации по профессиональной реабилитации инвалида, с учетом реабилитационного прогноза и потенциала, знаний и навыков, мотиваций к обучению и получению новой профессии.

В рамках государственной программы Российской Федерации «Доступная среда на 2011-2015 гг.» предусматривается выработка и внедрение моделей занятости населения в целях трудоустройства и переподготовки инвалидов. В настоящее время региональные программы, направленные на снижение напряженности на рынке труда органами государственной власти субъектов Российской Федерации, содействуют занятости инвалидов.

К приоритетным задачам государства, несомненно, относится обеспечение условий для получения качественного образования и последующего трудоустройства граждан с ограниченными возможностями здоровья. Таким образом, они смогут получать достойное вознаграждение и уровень их жизни повысится.

По мнению автора, нижеперечисленные методы окажутся действенными в решении проблемы трудоустройства инвалидов:

- $\quad$ меры по проектированию и приспособлению рабочих мест и рабочих помещений таким образом, чтобы они были доступны для лиц с различными видами нозологий;

- меры поддержки в использовании новых технологий, в разработке и производстве вспомогательных устройств, приспособлений;

- обеспечение надлежащего обучения и трудоустройства;

- меры для вовлечения инвалидов в разработку программ подготовки кадров и программ занятости в частном секторе;

- увеличение степени взаимодействия государства, организаций работников и нанимателями с организациями инвалидов и друг с другом;

- создание механизма резервирования определенных рабочих мест и профессий;

- содействие самозанятости;

- создание системы содействия сбыту продукции, производимой на предприятиях, применяющих труд инвалидов; 


\section{Политика и общество $5(101) \cdot 2013$}

- $\quad$ упрощение системы налогообложения для предприятий.

Комплексный подход к проблеме занятости и трудоустройства лиц с ограниченными возможностями здоровья со стороны работодателей, общества и государственных органов позволит нивелировать негативные последствия. Переход из статуса иждивенца в статус налогоплательщика будет способствовать улучшению качества жизни и положительной динамике показателей экономического роста.

\section{Библиография:}

1. Вовченко А.В. Трудоустройство людей с ограниченными возможностями - нестандартная работа. Материалы конференции, организованной Министерством здравоохранения и социального развития Российской Федерации и Международной организацией труда. Москва, 15 сентября 2011 г.

2. news.mail.ru/inregions/fareast/79/society/

3. Drake R.F. Understanding Disability Policies.-Basingstoke: Macmillan, 1999.

4. Е.Яковлева. Промежуточные люди. http://www. rg.ru/2003/12/23/sotial-strana.html/

5. Дискуссия по секции 4 по теме «Меры по содействию занятости граждан, испытывающих трудности на рынке труда». Материалы конференции, организованной Министерством здравоохранения и социального развития Российской Федера- ции и Международной организацией труда. Москва, 15 сентября 2011 г.

6. ФЗ от 27 июля 2010 г. № 210-Ф3 «Об организации предоставления государственных и муниципальных услуг», Постановление Правительства Российской Федерации от 30 ноября 2005 г. № 708 «Об утверждении правил обеспечения инвалидов собаками-проводниками, включая выплату ежегодной денежной компенсации расходов на содержание и ветеринарное обслуживание собак-проводников» и другие// Собрание законодательства Российской Федерации, 2010, № 31, ст. 4179; 2011, № 15, ст. 2038; № 27, ст. 3873, 3880; № 29, ст. 4291; № 30, ст. 4587. Собрание законодательства Российской Федерации, 2005, № 49, ст. 5226; 2011, № 16, ст. 2294.

\section{References (transliteration):}

1. Vovchenko A.V. Trudoustroystvo lyudey $\mathrm{s}$ ogranichennymi vozmozhnostyami - nestandartnaya rabota. Materialy konferentsii, organizovannoy Ministerstvom zdravookhraneniya i sotsial'nogo razvitiya Rossiyskoy Federatsii i Mezhdunarodnoy organizatsiey truda. Moskva, 15 sentyabrya $2011 \mathrm{~g}$.

2. Drake R.F. Understanding Disability Policies.-Basingstoke: Macmillan, 1999.

3. E.Yakovleva. Promezhutochnye lyudi. http://www. rg.ru/2003/12/23/sotial-strana.html/ 